\title{
KLASIFIKASI MOTIF SASIRANGAN BERBASIS FITUR GREY LEVEL CO- OCCURRENCE MATRIES MENGGUNAKAN METODE BACKPROPAGATION NEURAL NETWORK
}

\author{
Muhammad Saidi Rahman \\ Fakultas Teknologi Informasi \\ Universitas Islam Kalimantan Muhammad Arsyad Al Banjari Banjarmasin \\ Email : m.saidi.rahman@gmail.com
}

\begin{abstract}
ABSTRAK
Sasirangan adalah kain khas Kalimantan selatan yang dibuat dengan teknik jerujuk. Sasirangan memiliki banyak motif yang berjumlah sekitar 20 motif. Pada penelitian ini motif yang digunakan untuk klasifikasi sasirangan ada 3 motif yaitu Abstrak, Kulat Kurikit dan Hiris Gegatas dengan jumlah citra yang digunakan pada penitilian ini setiap motif ada 10 citra. Grey Level Co-occurrence Matrix (GLCM) digunakan untuk ekstrasi fitur pada gambar sasirangan. Dengan mengambil nilai 5 besaran dari GLCM yaitu Entropi, Korelasi, Kontras, Angular Second Moment (ASM) dan Inverse Different Moment (IDM) dari 4 sudut citra yang berbeda yaitu $0^{\circ}, 45^{\circ}, 90^{\circ}$ dan $135^{\circ}$. Selanjutnya hasil ekstrasi akan di klasifikasikan dengan menggunakan metode Backpropagation Neural Network dengan beberapa skenario pengujian melalui XValidation. Tipe validasi yang diuji yaitu Stratified Sampling, Linear Sampling dan Shuffled Sampling dengan ketentuan Number Validation 2 sampai 10. Hasil akurasi tertinggi pada number validation 10 dengan akurasi $95 \%$ pada ketiga tipa validasi.
\end{abstract}

Keywords : Sasirangan, Grey Level Co-occurrence Matrix(GLCM), Backpropagation Neural Network.

\section{PENDAHULUAN}

Suku Banjar di Kalimantan Selatan mempunyayi kain adat khas Banjar yang namanya Sasirangan. Sasirangan dibuat dengan teknik tusuk jelulur. Sejak tahun 2007, industry sasirangan ditetapkan sebagai salah satu dari sepuluh komoditi/produk/jenis usaha (KPJU) unggulan Kalimantan Selatan.

Sekarang ini motif sasisrangan beragam dan masih ada beberapa yang belum dikenal masyarakat. Hal inilah dianggap sebagai salah satu aspek yang menarik untuk diteliti menggunakan sains dan teknologi. Pada penelitian ini, mengadopsi tentang bagaimana pemprosesan citra dapat digunakan untuk mengklasifasikan fitur dari citra sasirangan.

Muhammad Dedy Rosyadi melakukan penelitian tentang pengenalan motif kain sasirangan dengan metode Template Matching.
Algoritma ini mencocokan setiap pixel pada suatu matriks citra input dengan citra yang digunakan sebagai template. Saat dilakukan eksperimen untuk mengenali pola motif pada sasirangan memiliki tingkat akurasi sebesar 83.33\%. akan tetapi metode ini masih memiliki kelemahan yaitu pada citra yang memiliki motif sama tetapi mempunyai ukuran yang berbeda.[1]

Zayid Mustafa yang melakukan penelitian tentang sasirangan dengan judul ekstraksi fitur motif sasirangan menggunakan algoritma naïve bayes berbasis color histogram dan GLCM. Penelitian ini memiliki tingkat akurasi yang tinggi sebagai ektraksi fitur dengan akurasi tertinggi mencapai $80 \%$ menggunakan metode GLCM dan menggunakan color histogram hanya mencapai 63.33\%.[2]

Neural Network merupakan metode yang banyak digunakan oleh peneliti pengenalan 
klasifikasi motif dimana memberikan hasil pengenalan dengan akurasi yang tinggi dan merupakan metode yang banyak digunakan pada bidang-bidang yang melibatkan pemecahan masalah pengelompokan dan pengenalan pola dengan menghasilkan keakuratan yang tinggi [3]. Dalam Pengenalan klasifikasi motif, Neural Network terbukti dapat memberikan akurasi pengenalan yang tinggi [4][5], dan algoritma yang banyak digunakan adalah Backpropagation.

\section{RUMUSAN MASALAH}

Berdasarkan latar belakang yang telah diuraikan diatas, dapat dirumuskan "Bagaimana motif sasirangan dapat diklasifikasikan dengan menggunakan fitur ekstraksi GLCM dan metode Backpropagation Neural Network".

\section{METODE PENELITIAN}

\section{Metode Pengumpulan Data}

Data terdiri dari 30 citra digital kain sasirangan yang didapat langsung oleh penelitian sebelumnya[1][2] yang terdiri dari 10 data citra motif Hiris Gagatas dengan label a menjadi class 1, 10 data citra motif Kulat Kurikit diberi label b menjadi class 2 dan 10 data citra motif Absrak diberi label c menjadi class 3. Berikut ini contoh dataset kain sasirangan berdasarkan jenis motifnya yang didapat dari penelitian
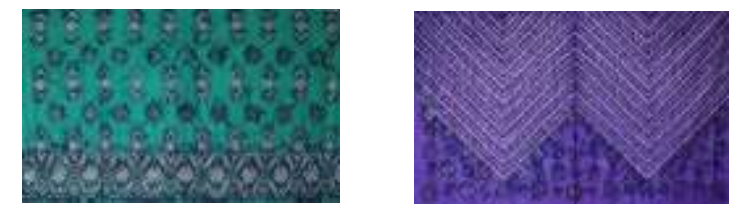

sebelumnya ${ }_{(a)}^{[1][2] . ~}$

Pada gambar 1, sampel citra a adalah motif hiris gegatas, sampel citra $b$ adalah motif kulat kurikit dan sampel citra c adalah motif abstrak.

\section{Metode Pengolahan Data}

(b)

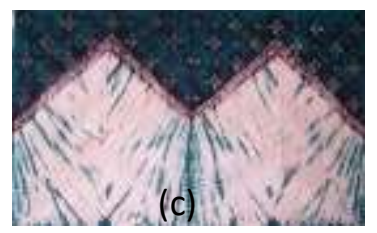

Gambar 1. Sampel Citra Sasirangan
Langkah-langkah yang dilakukan dalam tahap pengelohan data, yaitu:

a. Melakukan cropping bagian tepi frame foto tujuannya menghilangkan background foto sehingga hanya ada bagian kain sasirangan saja.

b. Kemudian ukuran foto di resize menjadi 800x444 piksel.

\section{Metode Yang Diusulkan}

Untuk proses ekstraksi kain sasirangan menggunakan GLCM dengan atribut yang digunakan hanya beberapa besaran yang diusulkan Haralick, Newsam dan Kammath (2005) yaitu hanya menggunakan lima besaran berupa angular second moment (ASM), contrast, inverse different moment (IDM), entropi dan korelasi. Setelah proses ekstraksi selesai dan nilai besaran dari citra sudah didapat, maka akan dilakukan proses klasifikasi dengan metode Backprogation Neural Network.

\section{Grey Level Co-occurrence Matrix (GLCM)}

GLCM menggunakan perhitungan tekstur pada orde kedua. Pengukuran tekstur pada orde pertama menggunakan perhitungan statistika didasarkan pada nilai piksel citra asli semata, seperti varians, dan tidak memperhatikan hubungan ketetanggaan piksel. Pada orde kedua, hubungan antarpasangan dua piksel citra asli diperhitungkan[6].

Untuk masing-masing citra sasirangan, perhitungan akan dilakukan secara 4 sudut yaitu sudut $00,450,900 `$ dan 1350 dengan nilai besaran yang dicari yaitu:

a. Kontras

Kontras merupakan ukuran keberadaan variasi aras keabuan piksel citra.

Kontras $=\sum_{n=1}^{L} n^{2}\left\{\sum_{|i-j|=n} \operatorname{GLCM}(i, j)\right\}$

b. Korelasi

Korelasi merupakan ukuran ketergantungan linear antar nilai aras keabuan dalam citra 


$$
\text { Korelasi }=\frac{\sum_{i=1}^{L} \sum_{j=1}^{L}(i j)\left(\operatorname{GLCM}(i, j)-\mu_{i}{ }^{\prime} \mu_{j}{ }^{\prime}\right.}{\sigma_{i}{ }^{\prime} \sigma_{j}{ }^{\prime}}(2)
$$

c. Entropi

Entropi menyatakan ukuran ketidakteraturan aras keabuan didalam citra. Nilainya tinggi jika elemen-elemen GLCM mempunyai nilai yang relatif sama. Nilai rendah jika elemen-elemen GLCM dengan dengan 0 atau 1.

Entropi

$$
=-\sum_{i=1}^{L} \sum_{j=1}^{L}(\operatorname{GLCM}(i, j) \log (\operatorname{GLCM}(i, j)
$$

d. Angular Second Moment (ASM)

ASM merupakan ukuran homogenitas (kemiripan) citra.

$$
A S M=\sum_{i=1}^{L} \sum_{j=1}^{L}\left(\operatorname{GLCM}(i, j)^{2}\right.
$$

e. Inverse Different Moment (IDM)

Fitur IDM digunakan untuk mengukur homogenitas.

$$
I D M=\sum_{i=1}^{L} \sum_{j=1}^{L} \frac{\left(G L C M(i, j)^{2}\right.}{1+(i-j)^{2}}
$$

\section{HASIL DAN PEMBAHASAN}

Setelah pengelohan dataset sasirangan dilakukan, maka langkah selanjutnya yaitu melakukan ekstrasi dataset menggunakan GLCM. Tapi sebelum di ekstraski, citra sasirangan di konversi menjadi grayscale terlebih dahulu baru kemudian dilanjutkan ke proses ekstrasi untuk mendapatkan nilai 5 besaran yang dari 4 sudut yang digunakan yaitu sudut $0^{0}, 45^{\circ}, 90^{\circ}, 135^{\circ}$. Berikut ini salah satu contoh citra sasirangan dengan nilai 5 besaran pada sudut $0^{0}$.

Tabel 1. Nilai 5 Besaran Citra Sasirangan

\begin{tabular}{ll} 
Citra Sasirangan & \multicolumn{1}{c}{ Nilai 5 Besaran } \\
ASM $0 \quad: 0.0013$ \\
IDM $0 \quad: 0.2688$ \\
ENTROPI $0: 78.067$ \\
KONTRAS $0:$ \\
2.98e+00 \\
KORELASI $0: 4.939$
\end{tabular}

Pada tabel 1 menampilkan nilai 5 besaran dari citra sasirangan pada sudut $0^{0}$. Selanjutnya proses akan mencari nilai 5 besaran dari seluruh citra pada 4 sudut. Setelah proses ekstrasi dilakukan dan semua nilai 5 besaran dari 4 sudut citra sudah didapat, langkah selanjutnya yaitu melakukan klasifikasi menggunakan metode Backpropagation Neural Network. Untuk proses klasifikasi, hasil dari nilai besaran dari 4 sudut tadi digabung menjadi sebuat dataset yang terdiri dari 20 atribut dan 1 buah label yang akan menjadi target class. Berikut ini format dataset yang digunakan dapat dilihat pada tabel 2.

Tabel 2. Format Dataset

\begin{tabular}{cllc}
\hline No & Nama Kolom & \multicolumn{1}{c}{ Satuan } & Role \\
\hline $\mathbf{1}$ & Label & Polynominal & Label \\
\hline $\mathbf{2}$ & ASM 0 & Real & Atribute \\
\hline $\mathbf{3}$ & IDM 0 & Real & Atribute \\
\hline $\mathbf{4}$ & Entropi 0 & Real & Atribute \\
\hline $\mathbf{5}$ & Kontras 0 & Real & Atribute \\
\hline $\mathbf{6}$ & Korelasi 0 & Real & Atribute \\
\hline $\mathbf{7}$ & ASM 45 & Real & Atribute \\
\hline $\mathbf{8}$ & IDM 45 & Real & Atribute \\
\hline $\mathbf{9}$ & Entropi 45 & Real & Atribute \\
\hline $\mathbf{1 0}$ & Kontras 45 & Real & Atribute \\
\hline $\mathbf{1 1}$ & Korelasi 45 & Real & Atribute \\
\hline $\mathbf{1 2}$ & ASM 90 & Real & Atribute \\
\hline $\mathbf{1 3}$ & IDM 90 & Real & Atribute \\
\hline $\mathbf{1 4}$ & Entropi 90 & Real & Atribute \\
\hline $\mathbf{1 5}$ & Kontras 90 & Real & Atribute \\
\hline $\mathbf{1 6}$ & Korelasi 90 & Real & Atribute \\
\hline $\mathbf{1 7}$ & ASM 135 & Real & Atribute \\
\hline $\mathbf{1 8}$ & IDM 135 & Real & Atribute \\
\hline $\mathbf{1 9}$ & Entropi 135 & Real & Atribute \\
\hline $\mathbf{2 0}$ & Kontras 135 & Real & Atribute \\
\hline $\mathbf{2 1}$ & Korelasi 135 & Real & Atribute \\
\hline & & &
\end{tabular}

Dari tabel 2 diatas, maka didapatlah dataset seperti berikut ini dari 5 besaran GLCM dari semua sudut yang digabungkan untuk digunakan sebagai pengujian dan eksperimen. Isi dataset untuk penilitian ini dapat dilihat pada tabel 3 berikut ini. 
Tabel 3. Dataset Citra Sasirangan Untuk Pengujian

\begin{tabular}{ccccccccc}
\hline LABEL & ASM 0 & IDM 0 & $\begin{array}{c}\text { ENTROPI } \\
\mathbf{0}\end{array}$ & $\begin{array}{c}\text { KONTRAS } \\
\mathbf{0}\end{array}$ & KORELASI 0 & $\ldots$ & KONTRAS & $\begin{array}{c}\text { KORELASI } \\
\mathbf{1 3 5}\end{array}$ \\
\hline $\mathbf{1}$ & $8,00 \mathrm{E}+00$ & 0.2352 & 79.480 & $5,86 \mathrm{E}+00$ & 6.144 .238 & $\ldots$ & $5,09 \mathrm{E}+00$ & 8.769 .299 \\
\hline $\mathbf{1}$ & $3,44 \mathrm{E}+00$ & 0.1720 & 87.512 & $4,10 \mathrm{E}+00$ & 8.167 .165 & $\ldots$ & $3,52 \mathrm{E}+00$ & $1,24 \mathrm{E}+07$ \\
\hline $\mathbf{1}$ & 0.0013 & 0.2688 & 78.067 & $3,34 \mathrm{E}+00$ & 4.939 .298 & $\ldots$ & $3,25 \mathrm{E}+00$ & 6.315 .728 \\
\hline $\mathbf{1}$ & 0.0026 & 0.2911 & 76.209 & $2,98 \mathrm{E}+00$ & 8.974 .699 & $\ldots$ & $2,82 \mathrm{E}+00$ & $1,16 \mathrm{E}+07$ \\
\hline $\mathbf{1}$ & $5,23 \mathrm{E}+00$ & 0.1892 & 84.212 & $4,76 \mathrm{E}+00$ & 6.096 .918 & $\ldots$ & $4,44 \mathrm{E}+00$ & 8.026 .830 \\
\hline$\ldots$ & $\ldots$ & $\ldots$ & $\ldots$ & $\ldots$ & $\ldots$ & $\ldots$ & $\ldots$ & $\ldots$ \\
\hline $\mathbf{3}$ & $4,61 \mathrm{E}+00$ & 0.2098 & 86.264 & $3,05 \mathrm{E}+00$ & 5.374 .249 & $\ldots$ & $2,87 \mathrm{E}+00$ & 8.493 .963 \\
\hline
\end{tabular}

Pada tabel 3, dataset terdiri dari 30 citra sasirangan. Setiap citra memiliki atribut nilai dari 5 besaran GLCM dari beberapa sudut.

Dataset untuk klasifikasi sudah didapatkan, selanjutnya dilakukan pembagian dataset untuk keperluan training dan testing. Pada eksperimen ini skala pembagian data training dan testing yaitu 80\%:20\% artinya $80 \%$ dataset akan dijadikan training dan $20 \%$ akan dijadikan data testing. Jadi dataset training berjumlah 24 dan data testing sebanyak 6 data.

Pada penelitian ini, pengujian dilakukan menggunakan metode Backpropagation Neural Network dengan sebanyak 3 sampling type yaitu Linear Sampling, Shuffled Sampling dan Stratified Sampling. Nilai parameter yang digunakan untuk metode BPNN seperti pada tabel 4 berikut ini.

Tabel 4. Parameter BPNN

\begin{tabular}{lll}
\hline No & Parameter & Nilai \\
\hline 1. & Traing Cycles & 500 \\
\hline 2. & Learning Rate & 0.3 \\
\hline 3 & Momentum & 0.2 \\
\hline
\end{tabular}

Hasil pengujian metode Backpropagation Neural Network pada 3 Sampling type dengan melakukan teknik pengujian nilai Fold X-Validation. Nilai Fold XValidation di uji dari 2 sampai 10. Untuk hasil akurasi yang didapat dari pengujian BPNN bisa dilihat pada tabel 5 berikut ini.
Tabel 5. Hasil Akurasi Pengujian

\section{X-Validation}

\begin{tabular}{cccc}
\hline $\begin{array}{c}\text { K- } \\
\text { Fold }\end{array}$ & \multicolumn{3}{c}{ Accuracy } \\
\cline { 2 - 4 } & $\begin{array}{c}\text { Stratified } \\
\text { Sampling }\end{array}$ & $\begin{array}{c}\text { Linear } \\
\text { Sampling }\end{array}$ & $\begin{array}{c}\text { Shuffled } \\
\text { Sampling }\end{array}$ \\
\hline $\mathbf{1 0}$ & $95 \%$ & $95 \%$ & $95 \%$ \\
\hline $\mathbf{9}$ & $94,44 \%$ & $94,44 \%$ & $94,44 \%$ \\
\hline $\mathbf{8}$ & $93,75 \%$ & $93,75 \%$ & $93,75 \%$ \\
\hline $\mathbf{7}$ & $92,86 \%$ & $92,86 \%$ & $92,86 \%$ \\
\hline $\mathbf{6}$ & $94,44 \%$ & $86,11 \%$ & $91,67 \%$ \\
\hline $\mathbf{5}$ & $93,33 \%$ & $83,33 \%$ & $93,33 \%$ \\
\hline $\mathbf{4}$ & $91,67 \%$ & $83,33 \%$ & $87,50 \%$ \\
\hline $\mathbf{3}$ & $94,44 \%$ & $66,67 \%$ & $83,33 \%$ \\
\hline $\mathbf{2}$ & $75 \%$ & $66,67 \%$ & 66,67 \\
\hline
\end{tabular}

Dari tabel 4 diatas menunjukan teknik Fold Cross Validation pada Stratified Sampling, Linear Sampling dan Shuffled Sampling memiliki akurasi dengan nilai tertinggi yang sama yaitu dengan akurasi $95 \%$ pada nilai K-Fold $=10$.

\section{PERBANDINGAN HASIL PENGUJIAN}

Penelitian tentang sasirangan sebelumnya sudah pernah dilakukan[1][2]. Pada penelitian ini dataset diambil dari penelitian sebelumnya untuk dijadikan sebagai penelitian dam untuk mendapatkan nilai akurasi yang lebih tinggi. Penelitian sebelumnya menggunakan ekstrasi dengan Histogram dan GLCM untuk diklasifikasi dengan metode Naïve Bayes. Pada 
penelitian sebelumnya hasil akurasi tertinggi terdapat pada ekstrasi menggunakan GLCM dengan akurasi tertinggi $80 \%$. Sedangkan akurasi tertinggi dengan menggunakan Histogram memiliki akurasi sebesar $63.33 \%$. melihat dari penelitian sebelumnya, penelitian ini jauh menghasilkan akurasi lebih tinggi dari sebelumnya dengan akurasi $95 \%$. Perbandingan dari penggunaan metode yang berbeda dapat dilihat pada tabel 6 .

Tabel 6. Hasil Perbadingan Akurasi

\begin{tabular}{ll}
\hline Metode yang digunakan & Akurasi \\
\hline GLCM + Naïve Bayes & $80 \%$ \\
\hline Histogram + Naïve Bayes & $63,33 \%$ \\
\hline GLCM + BPNN & $95 \%$ \\
\hline
\end{tabular}

\section{KESIMPULAN}

\begin{abstract}
Dari hasil penelitian yang telah dilakukan dengan menggunakan metode Backpropagation Neural Network dari hasil ekstraksi dari 5 besaran GLCM dapat mengenali dan mengklasifikasi citra motif kain sasirangan dengan akurasi tertinggi sebesar 95\%. Metode Backpropagation Neural Network berhasil memiliki akurasi klasifikasi tertinggi dari penelitian yang sebelumnya[1][2] yang memiliki akurasi $80 \%$ dengan menggunakan Naïve Bayes[2].
\end{abstract}

\section{DAFTAR PUSTAKA}

[1] Dedy, Muhammad Rosyadi, "Pengenalan Motif Kain Sasirangan Dengan Metode Template Matching”, 2015

[2] Mustafa, Zayid, "Ektraksi Fitur Motif Sasirangan Menggunakan Algoritma Naïve Bayes Berbasis Color Histogram dan Gray Level Co-occurrence Matrices(GLCM)", 2015

[3] D. Puspitaningrum, Pengantar Jaringan Syaraf Tiruan, Yogyakarta: Andi Ofset, 2006.

[4] N. Suciati, W. A. Pratomo, D. Purwitasari, "Batik Motif Classification using Color-
Texture-Based Feature Extraction and Backpropagation Neural Network," 2014.

[5] Kurniawardhani, Suciati, Arieshanti "Klasifikasi Citra Batik Menggunakan Metode Ekstraksi Ciri Tekstur yang Invariant Terhadap Rotasi”, JUTI Volume 12, Nomer 2, Juli 2014: 48 - 60

[6] Kadir, Abdul Susanto, Adhi. 2013. Teori dan aplikasi pengolahan citra, 